\title{
EFSUMB multidisciplinary guidelines and recommendations on the use of musculoskeletal ultrasound in clinical practice: what else?
}

\section{Esperanza Naredo}

Department of Rheumatology, Bone and Joint Research Unit. Hospital Universitario Fundación Jiménez Díaz, IIS Fundación Jiménez Díaz, and Universidad Autónoma de Madrid, Madrid, Spain

The musculoskeletal (MSK) system is essential for a fully normal life. This system of the human body can be affected by multiple diseases and disorders of very different etiology, from autoimmune, inflammatory, infectious, microcrystalline, degenerative, overload or traumatic. This is why multiple medical or health disciplines are involved in the diagnosis, management and treatment of MSK disorders. In the clinical care of MSK diseases, imaging techniques play an essential role in increasing diagnostic accuracy and monitoring response to treatment. In particular, ultrasound (US), whose application to the MSK system began about 25 years ago, has developed a great deal technologically and spread rapidly among health disciplines in recent years. It is a very valuable tool, complementary to the clinical workup, which facilitates diagnosis and considerably improves the management of patients with peripheral and some axial MSK conditions. In addition to its unquestionable value as an extension and enhancement of clinical skills, US plays an essential and unique role in diagnostic or therapeutic MSK injections, as it makes it possible to guide the injection or biopsy needles safely and effectively to the target structure of the procedure.

Currently, a large and growing number of specialties focused on the MSK system use MSK US in their daily clinical practice. Undoubtedly, the MSK system, although it can suffer from a wide spectrum of diseases, is only one. On the other hand, MSK US follows a rigorous

Received Accepted

Med Ultrason

2021, Vol. 23, No 4, 381-382

Corresponding author: Esperanza Naredo

Department of Rheumatology, Bone and Joint

Research Unit, Hospital Universitario Fundación

Jiménez Díaz and Autónoma University

Av. Reyes Católicos, 2

28040 Madrid. Spain

Phone: +34 915504978

E-mail: enaredo@ser.es scanning method and interpretation of findings, normal or pathological. However, the focus of interest and the logistical approach in performing US depends on the type of pathological process studied and the medical specialty involved. Therefore, although during the last decades, a great effort has been made by different scientific societies, based on the best available scientific evidence, to reach a consensus on the indications and appropriate use of MSK US in clinical practice [1-7], these products have been mostly made by and addressed to users of a specific specialty or discipline.

To the best of our knowledge, for the first time, international guidelines and recommendations have been developed for the use of MSK US from a broad multidisciplinary approach, sponsored by the European Federation of Societies for Ultrasound in Medicine and Biology (EFSUMB) $[8,9]$. Thirty-six physicians with extensive experience in MSK ultrasound from 7 different specialties (i.e. rheumatology, radiology, orthopedic surgery, physical and rehabilitation medicine, pediatrics, dermatology, anesthesiology), 4 research fellows and 1 methodologist from 15 European countries comprised the taskforce that generated them. For its elaboration, the methodology endorsed by EFSUMB [10] was followed. The work was divided, on the one hand, into MSK structures evaluable by US and, on the other hand, into anatomical MSK areas. In addition, essential aspects such as general considerations, US techniques, education, terminology, and safety were also included, as well as a section dedicated to pediatrics and other to US-guided procedures. As a result of this multidisciplinary effort, 82 consensal recommendations were developed, based on the best available scientific evidence. Furthermore, the text supporting the recommendations included sections on an extensive update on the multidisciplinary clinical indications for the technique, its limitations and artefacts and an exposition of practical points on its applicability for each structure, anatomical area and field of application. 
Authors from different MSK specialties collaborated on each subchapter and the final product was subjected to supervision, opinion and full agreement by the entire multidisciplinary group. Obviously, each author worked in the field in which they had the most experience and developed his clinical practice according to their specialty. However, all collaborated in the evaluation of the scientific evidence and in the drafting of the recommendations, as well as finally approving them. We firmly believe that this multidisciplinary approach, although it sometimes slowed down the task due to the different points of view of the disciplines on the same subject that frequently occur, considerably enriched the representativeness of the users of MSK US and the capacity for implementation of the final product by the MSK scientific community.

Another important aspect to keep in mind is that these guidelines and recommendations are not only addressed to healthcare professionals who perform MSK UD, but also to those who are not ultrasonographers. It is essential that all MSK specialists are aware of the applications and indications, i.e., what to expect and what not to expect, as well as the limitations of MSK ultrasound in patients seen by their specialty and other related specialties. This will promote more realistic and better clinically oriented applications of MSK US and, therefore, more cost-effective and efficient use of the technique for health provider organizations, for the professionals who request and perform it, and especially for patients, whose care and attention is the focus of the healthcare system.

In conclusion, the dissemination of these EFSUMB guidelines and recommendations among the multidisciplinary MSK community is expected to optimize the quality of the use of MSK ultrasound in the clinical care process of patients with MSK diseases.

\section{References}

1. Colebatch AN, Edwards CJ, Østergaard M, et al. EULAR recommendations for the use of imaging of the joints in the clinical management of rheumatoid arthritis. Ann Rheum Dis 2013;72:804-814.

2. Colebatch-Bourn AN, Edwards CJ, Collado P, et al. EULAR-PReS points to consider for the use of imaging in the diagnosis and management of juvenile idiopathic arthritis in clinical practice. Ann Rheum Dis 2015;74:1946-1957.

3. Mandl P, Navarro-Compán V, Terslev L, et al. EULAR recommendations for the use of imaging in the diagnosis and management of spondyloarthritis in clinical practice. Ann Rheum Dis 2015;74:1327-1339.

4. Sakellariou G, Conaghan PG, Zhang W, et al. EULAR recommendations for the use of imaging in the clinical management of peripheral joint osteoarthritis. Ann Rheum Dis 2017;76:1484-1494.

5. Sconfienza LM, Albano D, Allen G, et al. Clinical indications for musculoskeletal ultrasound updated in 2017 by European Society of Musculoskeletal Radiology (ESSR) consensus. Eur Radiol 2018;28:5338-5351.

6. Siddle HJ, Mandl P, Aletaha D, et al. The EULAR points to consider for health professionals undertaking musculoskeletal ultrasound for rheumatic and musculoskeletal diseases. Ann Rheum Dis 2018;77:311-313.

7. Tagliafico AS, Wilson D, Sconfienza LM; European Society of Musculoskeletal Radiology (ESSR) Research Committee. Encouraging MSK imaging research towards clinical impact is a necessity: opinion paper of the European Society of Musculoskeletal Radiology (ESSR). Eur Radiol 2019;29:3410-3413.

8. Fodor D, Rodriguez-Garcia SC, Cantisani C, et al. The EFSUMB Guidelines and Recommendations for Musculoskeletal Ultrasound - Part I: Extraarticular Pathologies. Ultraschall Med 2021; doi:10.1055/a-1562-1455.

9. Naredo E, Rodriguez-Garcia SC, Terslev L, et al. The EFSUMB Guidelines and Recommendations for Musculoskeletal Ultrasound - Part II: Joint Pathologies, Pediatric Applications, and Guided Procedures. Ultraschall Med 2021; doi: 10.1055/a-1640-9183.

10. Jenssen C, Gilja OH, Serra AL, et al. European Federation of Societies for Ultrasound in Medicine and Biology (EFSUMB) Policy Document Development Strategy - Clinical Practice Guidelines, Position Statements and Technological Reviews. Ultrasound Int Open 2019;5:E2-E10. 